\title{
ESTUDO DA SECAGEM DA FIBRA RESIDUAL DO MARACUJÁ DRYING STUDY OF PASSION FRUIT RESIDUAL FIBER
}

\author{
Rosinelson S. PENA ${ }^{1}$; Dayse M. S. SILVA² Nilson B. MENDONÇA ${ }^{2}$; Marcos D. C. ALMEIDA ${ }^{2}$ \\ ${ }^{1}$ FEA/ITEC/UFPA - Campus Universitário do Guamá - Belém - PA - Brasil \\ ${ }^{2}$ Engenheiro Químico - Universidade Federal do Pará - Belém - PA - Brasil \\ 1rspena@ufpa.br
}

\begin{abstract}
Resumo
Buscou-se viabilidade tecnológica, através da secagem, para o aproveitamento do segundo resíduo da industrialização do suco de maracujá, produzido por uma indústria Paraense. O resíduo foi submetido à caracterização físico-química, obtendo como composição: $83 \%$ de umidade; 1,8\% de proteína, 0,2\% de gordura, 0,6\% de cinzas, 7,1\% de fibra alimentar total e 7,3\% de sólidos solúveis. Estudou-se a cinética de secagem do resíduo, em estufa com recirculação de ar, nas temperaturas de 70,80 e $90^{\circ} \mathrm{C}$. A qualidade higiênico-sanitária do produto foi constatada através de análises microbiológicas. Obtiveram-se informações sobre o comportamento higroscópico do produto, através de isotermas de adsorção e dessorção de umidade a $25^{\circ} \mathrm{C}$. O produto apresentou isotermas do tipo III e umidade equivalente à monocamada de 8,3 $\mathrm{g} \mathrm{H}_{2} \mathrm{O} / 100 \mathrm{~g}$ b.s. Comprovou-se a aplicabilidade do modelo GAB na predição das isotermas de adsorção e dessorção de umidade para o produto. Com base nos parâmetros de secagem, sensorial e higroscópico, sugere-se secar o resíduo a $70^{\circ} \mathrm{C}$, seguida de secagem complementar a $90^{\circ} \mathrm{C}$.
\end{abstract}

Palavras-chave: resíduo; maracujá amarelo; secagem; isoterma.

\section{Introdução}

O Brasil destaca-se no mercado internacional pela produção de maracujá, devido à extensão de área, clima privilegiado, relevo pouco acidentado e inúmeras outras características favoráveis ao desenvolvimento da cultura (MAARA, 1996).

O Pará é um dos maiores produtores nacionais de maracujá amarelo (Passiflora edulis), por apresentar características climáticas favoráveis à cultura (Silva, 2002). É a espécie mais cultivada por ser mais vigorosa, se adaptando mais facilmente aos dias quentes, apresentar frutos de maior tamanho, maior produção, maior acidez total ( $\mathrm{pH}$ de 2,5 a 3,0) e maior rendimento em suco (ITAL, 1980; LIMA et al., 1994).

Entre as indústrias alimentares instaladas no Estado do Pará, merecem destaque, pelo volume de produção e disponibilidade de matéria prima, as de beneficiamento de suco de frutas; 
destacando-se o maracujá. Essa indústria gera um elevado volume de rejeito industrial, constituído por cascas, sementes e "bagaços", os quais por apresentarem elevado teor de açúcares estão susceptíveis a processos fermentativos, exalando mau cheiro nos lugares de descarga e servindo de foco para a presença de animais e proliferação de insetos.

De acordo com ITAL (1980) o maracujá é constituído por 52\% de casca, 34\% de suco e $14 \%$ de sementes. A maior parte do resíduo gerado na produção do suco de maracujá no Pará é descartada e a outra é utilizada na alimentação animal. Um dos objetivos das indústrias de alimentos é encontrar formas de aproveitar os resíduos gerados, para que os mesmos possam ser revertidos em benefícios financeiros para a mesma e para minimizar ou até evitar impactos ambientais.

Os rejeitos gerados na produção do suco de maracujá (casca e material fibroso) apresentam características próprias, podendo-se destacar a presença de macronutrientes, como: açúcares, proteínas e principalmente fibras alimentares; além de micronutrientes como vitaminas (ITAL, 1980; SOUZA e SANDI, 2001). Essas particularidades reforçam mais ainda a necessidade de buscar alternativas para o aproveitamento dos mesmos.

É importante apresentar alternativa de utilização do resíduo para fins alimentares, como na composição de matinais; no enriquecimento de produtos, principalmente no que se refere ao teor e fibras alimentares (FERREIRA, 2004b; MENDONÇA, 2005); como ração animal ou como fonte de pectina (FERREIRA, 2004a). De acordo com MENDONÇA (2005) o segundo resíduo da industrialização do suco de maracujá amarelo apresenta um teor em fibras alimentares superior a $62 \%$, quando representado sobre a matéria seca.

Baseado nas propriedades físicas e papéis fisiológicos, as fibras alimentares podem ser classificadas como solúveis e insolúveis (MAHAN e STUMP, 1998). De acordo com PEREIRA (2002) algumas das funções das fibras solúveis são: retardar a passagem intestinal, o esvaziamento gástrico e a absorção da glicose, ajudando a reduzir o colesterol no soro sangüíneo; já as fibras insolúveis aceleram o trânsito intestinal, aumentando o volume fecal, desacelerando a hidrólise da glicose e contribuindo para a redução de alguns males do colón.

O objetivo do trabalho é estudar a secagem, em estufa com recirculação de ar, do segundo resíduo gerado na produção do suco de maracujá (resíduo fibroso), além de avaliar condições de armazenamento para o produto, através de isotermas de sorção de umidade; visando apresentar uma alternativa para o aproveitamento do mesmo. 


\section{Material e métodos}

\subsection{Matéria prima}

A matéria-prima estudada foi o segundo resíduo (fibra residual) da produção do suco do maracujá amarelo (Passiflora edulis), fornecido pela Indústria SUCASA - Sucos da Amazônia S.A, localizada no município de Castanhal (PA). O resíduo, depois de extraído foi congelado a $-18^{\circ} \mathrm{C}$, sendo descongelado a $5^{\circ} \mathrm{C}$ apenas para a realização dos ensaios experimentais.

\subsection{Métodos}

\subsubsection{Caracterização físico-química}

Foram submetidos a análises físico-químicas o resíduo estudado e o produto obtido. Determinou-se com base nas metodologias propostas pela AOAC (1997): umidade, em estufa a $105^{\circ} \mathrm{C}$, até peso constante; proteínas totais, pelo método de Kjeldahl, utilizando fator de conversão de nitrogênio para proteína de 6,25; resíduo mineral fixo (cinzas), por calcinação em mufla a $550^{\circ} \mathrm{C}$, até peso constante; gordura (extrato etéreo), através de extração com éter de petróleo; teor de sólidos solúveis, por refratometria e fibras alimentares totais, pelo método enzimático proposto por PROSKY et al. (1988).

\subsubsection{Determinações microbiológicas}

Foram avaliados microbiologicamente o resíduo e o produto obtido. Foram pesquisadas as ocorrências de coliformes a $45^{\circ} \mathrm{C}$ e Salmonella sp., para o resíduo e coliformes a $45^{\circ} \mathrm{C}, \mathrm{B}$. Cereus e Salmonella sp., para o produto, baseados em metodologias propostas por VANDERZANT e SPLITTSTOESSER (1992).

\subsubsection{Secagem do resíduo}

$\mathrm{O}$ resíduo, após descongelado a $5^{\circ} \mathrm{C}$, foi retirado do refrigerados para atingir a temperatura ambiente $\left(\approx 25^{\circ} \mathrm{C}\right) .100 \mathrm{~g}$ do material foram dispostos em bandeja de $20,3 \times 29,7(\mathrm{~cm})$, de maneira que formasse uma camada delgada sobre sua base. O conjunto foi submetido à secagem em estufa com circulação de ar marca Memmert, devidamente instrumentada, com capacidade de aquecimento até $200^{\circ} \mathrm{C}$ e precisão de $\pm 1^{\circ} \mathrm{C}$.

Os ensaios de secagem foram realizados a 70,80 e $90^{\circ} \mathrm{C}$. Utilizou-se esta faixa de temperatura visto que abaixo de $70^{\circ} \mathrm{C}$ o processo de secagem tornou-se muito lento e acima de $90^{\circ} \mathrm{C}$ podem ocorrer alterações indesejáveis em produtos alimentícios, como desnaturação de proteínas; comprometendo a qualidade dos mesmos. 
O acompanhamento da secagem foi feito através da pesagem do conjunto (bandeja + resíduo) a cada 10 minutos, na primeira hora; a cada 20 minutos, na segunda e a cada 30 minutos, a partir da terceira. A pesagem foi interrompida no momento que não havia mais variação significativa da massa (variância inferior a 5\%). A umidade final do produto foi determinada por secagem em estufa a $105^{\circ} \mathrm{C}$, durante 24 horas.

Para avaliar a cinética do processo de secagem do resíduo foram construídas curvas de taxa de secagem (taxa de secagem versus umidade e taxa de secagem versus tempo), utilizando a Equação 1. Os valores de $\left(\mathrm{dX}_{\mathrm{bs}} / \mathrm{dt}\right)$ foram obtidos a partir das derivadas das equações da reta (Equação 2) e exponencial (Equação 3); ajustadas aos dados experimentais de secagem ( $\mathrm{X}_{\mathrm{bs}}$ versus $\mathrm{t}$ ), de acordo com o comportamento linear ou exponencial.

$$
\begin{gathered}
\mathrm{W}_{\mathrm{T}}=\frac{\mathrm{m}}{\mathrm{A}} \cdot\left(-\frac{\mathrm{d} \mathrm{X}_{\mathrm{bs}}}{\mathrm{dt}}\right) \\
\mathrm{X}_{\mathrm{bs}}=\mathrm{a}+\mathrm{b} \cdot \mathrm{t} \\
\mathrm{X}_{\mathrm{bs}}=\mathrm{c} \cdot \mathrm{e}^{-\mathrm{k} \cdot \mathrm{t}^{\mathrm{n}}}
\end{gathered}
$$

onde: $\mathrm{X}_{\mathrm{bs}}=$ umidade $(\mathrm{g} / 100 \mathrm{~g}$ b.s. $) ; \mathrm{t}=$ tempo $(\mathrm{min}) ; \mathrm{W}_{\mathrm{T}}=$ taxa de secagem $\left(\mathrm{g} / \mathrm{cm}^{2} . \mathrm{h}\right) ; \mathrm{m}=$ peso seco, $\mathrm{A}=$ área da superfície exposta a secagem; a, b, c, k e n constantes.

\subsubsection{Avaliação higroscópica do produto}

Foram construídas isotermas de sorção de umidade para o produto, a partir dos dados de adsorção e dessorção obtidos a $25^{\circ} \mathrm{C}$, para avaliar o comportamento do ganho e perda de umidade, respectivamente e estabelecer parâmetros de secagem e armazenamento para o produto.

Na obtenção dos dados de adsorção, amostras de 1,5 g ( $\pm 5 \mathrm{~g})$ do produto, acondicionadas em recipientes próprios do aparelho de $\mathrm{a}_{\mathrm{w}}$, foram submetidas à desidratação complementar. $\mathrm{O}$ processo foi realizado em dessecador contendo sílica-gel na base, sob vácuo e à temperatura ambiente $\left(\approx 25^{\circ} \mathrm{C}\right)$, por um período de 24 horas. Em seguida as amostras foram transferidas para um dessecador contendo água na base.

Para obtenção dos dados de dessorção, as mesmas amostras submetidas à adsorção foram mantidas, por 24 horas, em dessecador contendo água na base, na temperatura de trabalho $\left(25^{\circ} \mathrm{C}\right)$, em ambiente com variações de temperatura de no máximo $\pm 1^{\circ} \mathrm{C}$; para que ocorresse a umidificação das mesmas. Em seguida as amostras foram transferidas para dessecador contendo sílica-gel na base.

Nos dois casos, os dessecadores contendo as amostras foram mantidos em estufa DBO a $25^{\circ} \mathrm{C}$ ), com variação máxima de $\pm 1^{\circ} \mathrm{C}$, de onde eram retiradas amostras, em duplicata, em tempos 
crescentes (pseudo-equilíbrio), para determinação da umidade, por diferença de peso, e da atividade de água, em higrômetro AQUAlab 3TE da Decagon. Durante os processos de sorção as amostras foram submetidas a acompanhamento visual, para observar alterações visualmente perceptíveis, como: "caking", escurecimento e crescimento de fungos.

O modelo matemático proposto por Guggenheim-Anderson-De Boer (GAB) (MAROULIS et al., 1988) (Equação 4) foi ajustado aos dados de adsorção e dessorção, por regressão não linear, com auxílio do aplicativo STATISTICA for Windows 5.5. Através dos ajustes foi possível predizer a umidade equivalente à monocamada $\left(\mathrm{m}_{\mathrm{o}}\right)$.

$$
\frac{\mathrm{m}}{\mathrm{m}_{\mathrm{o}}}=\frac{\mathrm{c} \cdot \mathrm{k} \cdot \mathrm{a}_{\mathrm{w}}}{\left(1-\mathrm{k} \cdot \mathrm{a}_{\mathrm{w}}\right)\left(1-\mathrm{k} \cdot \mathrm{a}_{\mathrm{w}}+\mathrm{c} \cdot \mathrm{k} \cdot \mathrm{a}_{\mathrm{w}}\right)}
$$

onde: $\mathrm{m}$ é umidade (g/100 g b.s.); $\mathrm{a}_{\mathrm{w}}$ atividade de água; $\mathrm{m}_{\mathrm{o}}$ monocamada (g/100 g b.s.); c constante de Guggenheim; k fator relacionado as multicamadas.

\section{Resultados e discussão}

\subsection{Avaliação físico-química e microbiológica}

As composições do resíduo e dos produtos obtidos após secagem a $70^{\circ} \mathrm{C}(\mathrm{F} 70), 80^{\circ} \mathrm{C}(\mathrm{F} 80)$ e $90^{\circ} \mathrm{C}$ (F90) e moagem, os quais podem ser classificados como farinha, de acordo com a Resolução RDC nº 263 da ANVISA (BRASIL, 2005), são apresentados na Tabela 1. As farinhas mostraram-se ricas em sólidos solúveis (açúcares), o que lhes atribuiu sabor agradável e característico do maracujá. Apresentaram teor considerável de proteína (10,6\% b.s.) e excepcional de fibras alimentares (40,2\% b.s.); o que permite classificá-las como ricas neste constituinte; apresentando-se como uma alternativa para emprego em dietas que necessitem do mesmo.

Tabela 1 - Composição do resíduo utilizado e das farinhas obtidas.

\begin{tabular}{lcccc}
\cline { 2 - 5 } & \multicolumn{3}{c}{ Composição (g/100 g b.u.) } \\
\hline Constituinte & Resíduo & F70 & F80 & F90 \\
\hline Umidade & 83,0 & 11,0 & 9,0 & 8,7 \\
Proteína & 1,8 & 11,3 & 11,5 & 11,6 \\
Gordura & 0,2 & 1,0 & 1,0 & 1,0 \\
Cinzas & 0,6 & 3,1 & 3,2 & 3,2 \\
Fibras alimentares totais & 7,1 & 35,8 & 36,6 & 36,7 \\
Sólidos solúveis & 7,3 & 37,8 & 38,7 & 38,8 \\
\hline
\end{tabular}

b.u. = base úmida. 
$\mathrm{Na}$ Tabela 2 são apresentados os resultados das análises microbiológicas, as quais foram submetidos o resíduo e as farinhas. De acordo com os padrões estabelecidos pela legislação brasileira (BRASIL, 2001), os produtos encontram-se apropriados para consumo.

Tabela 2 - Parâmetros microbiológicos do resíduo utilizado e das farinhas obtidas.

\begin{tabular}{ccccc}
\hline Análises & Resíduo & Farinha $\left(\mathbf{7 0}^{\circ} \mathbf{C}\right)$ & Farinha $\left(\mathbf{8 0}^{\circ} \mathbf{C}\right)$ & Farinha $\left(\mathbf{9 0}^{\circ} \mathbf{C}\right)$ \\
\hline Salmonella $(\mathrm{em} 25 \mathrm{~g})$ & Ausente & Ausente & Ausente & Ausente \\
Coliformes a $45^{\circ} \mathrm{C}$ & $<3 \mathrm{NMP} / \mathrm{g}$ & $<3 \mathrm{NMP} / \mathrm{g}$ & $<3 \mathrm{NMP} / \mathrm{g}$ & $<3 \mathrm{NMP} / \mathrm{g}$ \\
Bacillus cereus & - & $<10^{1} \mathrm{UFC} / \mathrm{g}$ & $<10^{1} \mathrm{UFC} / \mathrm{g}$ & $<10^{1} \mathrm{UFC} / \mathrm{g}$ \\
\hline
\end{tabular}

\subsection{Estudo da secagem do resíduo}

$\mathrm{Na}$ Figura 1 são apresentadas as curvas de secagem do resíduo, nas três temperaturas estudadas. Para atingir umidades de equilíbrio de 12,3 g/100 g b.s., 9,9 g/100 g b.s. e 9,6 g/100 g b.s., foram necessários $370 \mathrm{~min}, 340 \mathrm{~min}$ e $150 \mathrm{~min}$, a 70,80 e $90^{\circ} \mathrm{C}$, respectivamente.

Figura 1 - Curvas de secagem da fibra residual do maracujá amarelo.

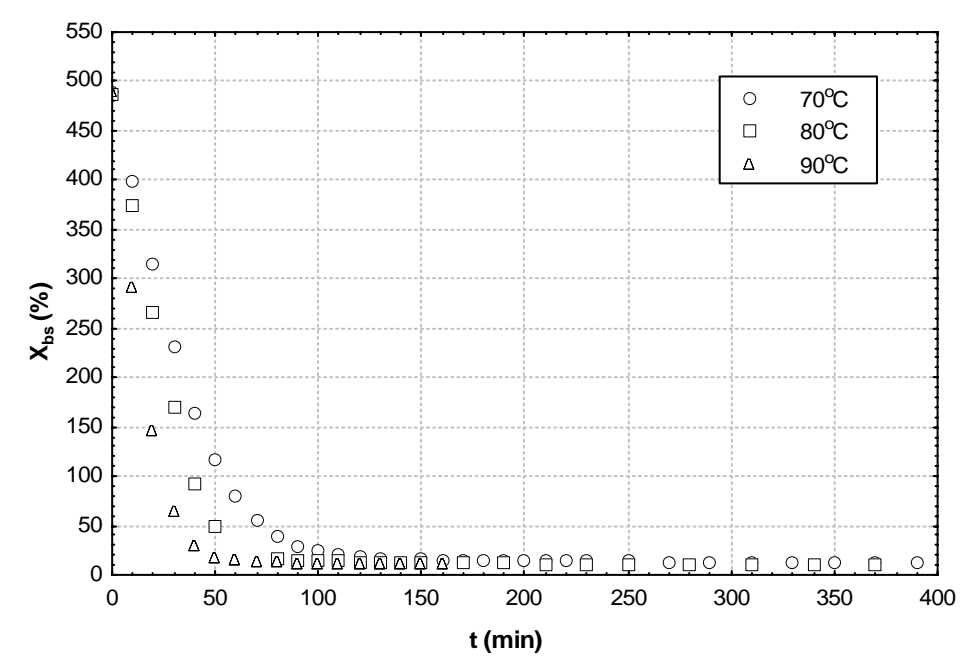

O aumento na temperatura de secagem provocou escurecimento visualmente perceptível dos produtos (Figura 2), o qual pode ser justificado pela ocorrência da reação de Maillard, devido a presença de proteínas e açúcares redutores no resíduo ou, menos provável, devido a reações de caramelização, em função do elevado teor de açúcares no resíduo (>65\% b.s.). Estas reações ocorrem preferencialmente em temperaturas superiores a $100^{\circ} \mathrm{C}$. 
Figura 2 - Visualização das farinhas obtidas nas diferentes temperaturas.

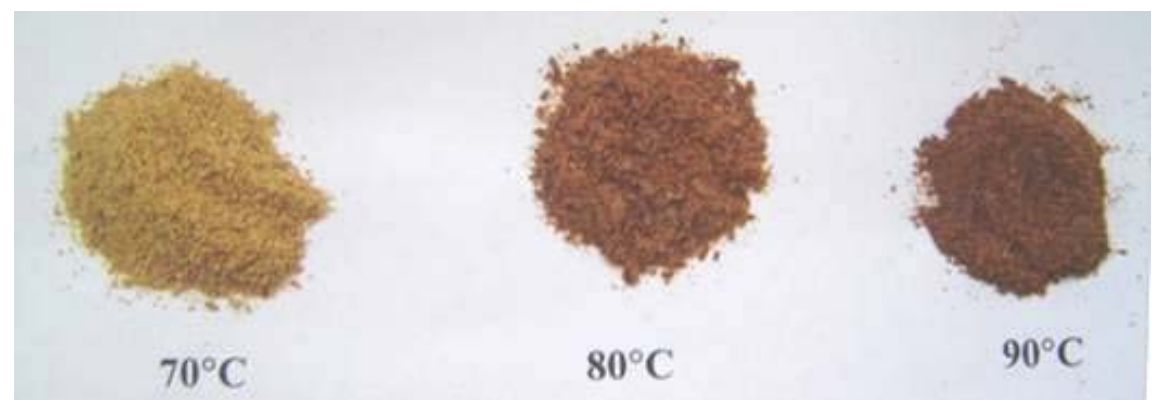

De acordo com o exposto, embora as secagens a 70 e $80^{\circ} \mathrm{C}$ tenham necessitado de tempos praticamente iguais, e mais que o dobro da realizada a $90^{\circ} \mathrm{C}$, por questões sensoriais a preferência deve ser dada à secagem realizada a $70^{\circ} \mathrm{C}$; desde que não haja restrição quanto à umidade final do produto, que neste caso é maior e por isso pode torná-lo mais susceptível a processos degradativos.

Outro fator que chama atenção é o fato dos produtos não terem atingido umidades de equilíbrio inferiores a 9,5 g/100 g b.s., em nenhuma das condições de secagem. Neste caso, tal comportamento pode ser justificado pelo elevado teor de sólidos solúveis (açúcares), que apresentam forte afinidade pelas moléculas de água, exercem barreira à retirada da fração residual de água.

Os parâmetros de ajuste dos modelos linear e exponencial, aos dados de secagem, são apresentados na Tabela 3 , os quais foram utilizados na obtenção das curvas de taxa de secagem (Figuras 3 e 4).

Tabela 3 - Parâmetros de ajuste dos modelos linear e exponencial aos dados de secagem.

\begin{tabular}{|c|c|c|c|c|c|c|}
\hline \multirow{2}{*}{ Secagem } & \multicolumn{5}{|c|}{ Constantes dos modelos } & \multirow{2}{*}{$\mathbf{r}^{2}$} \\
\hline & $\mathbf{a}$ & b & C & $\mathbf{k}$ & $\mathbf{n}$ & \\
\hline $70^{\circ} \mathrm{C}$ & 482,6 & $-8,2$ & 2,2 & $-32,0$ & $-0,54$ & 0,9900 \\
\hline $80^{\circ} \mathrm{C}$ & 482,6 & $-10,6$ & 3,8 & $-49,5$ & $-0,75$ & 0,9950 \\
\hline $90^{\circ} \mathrm{C}$ & 479,8 & $-17,2$ & 2,2 & $-27,2$ & $-0,62$ & 0,9920 \\
\hline
\end{tabular}


Figura 3 - Curvas de taxa de secagem da fibra residual do maracujá amarelo $\left(\mathrm{W}_{\mathrm{T}}\right.$ versus $\left.\mathrm{X}_{\mathrm{bs}}\right)$.

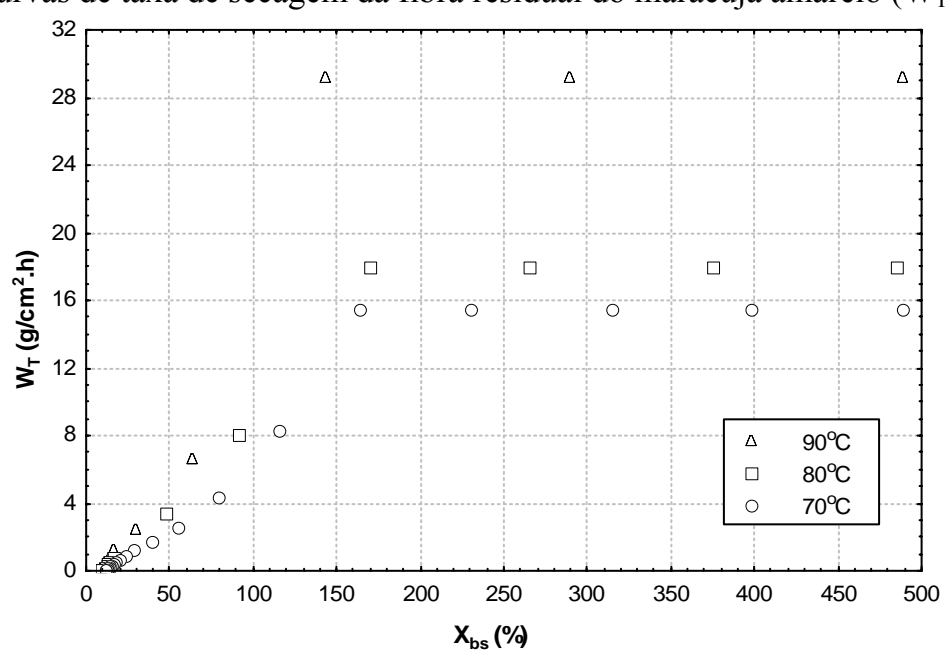

Figura 4 - Curvas de taxa de secagem da fibra residual do maracujá amarelo $\left(\mathrm{W}_{\mathrm{T}}\right.$ versus $\left.\mathrm{t}\right)$.

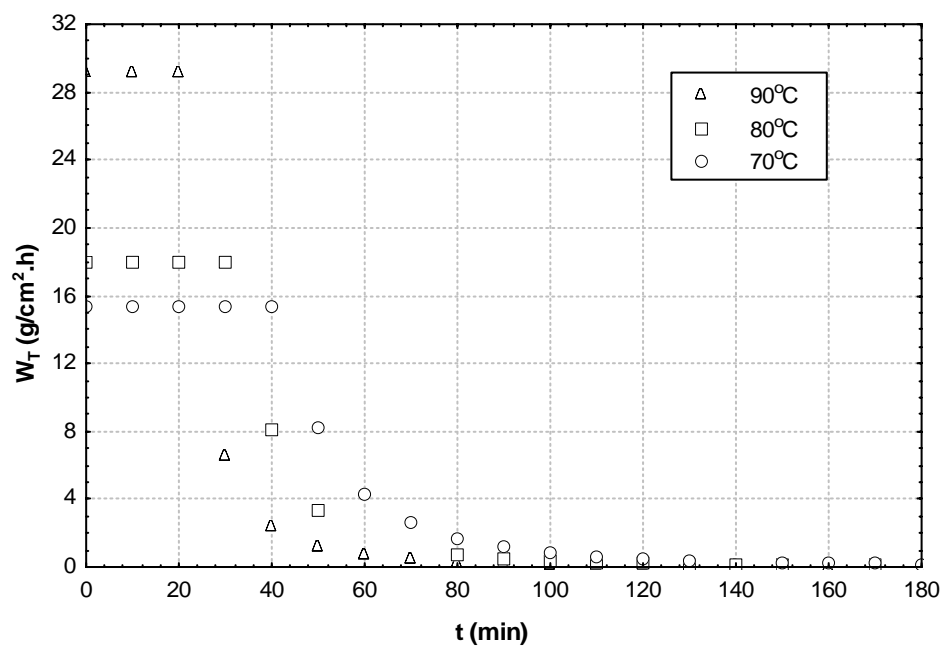

De acordo com os dados de secagem e taxa de secagem, aproximadamente $2 / 3$ da umidade do resíduo se apresentava na forma de água livre, senda eliminada a uma taxa de secagem constante, em tempos de $20 \mathrm{~min}, 30 \mathrm{~min}$ e $40 \mathrm{~min}$, a 90,80 e $70^{\circ} \mathrm{C}$, respectivamente.

O comportamento da taxa de secagem decrescente se manteve nas diferentes condições de secagem e o tempo a taxa decrescente foi, no mínimo, seis vezes e meia superior ao a taxa constante, comprovando a presença de constituintes com elevada afinidade por moléculas de água (açúcares) no resíduo, os quais oferecem grande resistência à redução da umidade.

\subsection{Avaliação higroscópica do produto}

$\mathrm{Na}$ avaliação higroscópica foi utilizado o produto obtido a $70^{\circ} \mathrm{C}$. Os dados de adsorção e dessorção de umidade são apresentados na Tabela 4 e as respectivas isotermas de sorção nas Figuras 5 e 6; as quais são classificadas com do tipo III, de acordo com SALWIN (1959). Não 
foram observadas mudanças na fluidez, escurecimento ou crescimento de fungos nas amostras, durante aos processos de adsorção e dessorção. Comportamento semelhante foi observado por WAUGHON e PENA (2007) para a fibra residual do abacaxi.

Tabela 4 - Dados de sorção de umidade para a farinha da fibra residual do maracujá amarelo.

\begin{tabular}{|c|c|c|c|}
\hline \multicolumn{2}{|c|}{ Adsorção* } & \multicolumn{2}{|c|}{ Dessorção* } \\
\hline $\mathbf{a}_{\mathrm{w}}$ & m (g $\mathrm{H}_{2} \mathrm{O} / 100 \mathrm{~g}$ b.s.) & $\mathbf{a}_{\mathbf{w}}$ & m (g H $\mathrm{H}_{2} \mathrm{O} / 100 \mathrm{~g}$ b.s.) \\
\hline 0,29 & 2,78 & 0,94 & 80,90 \\
\hline 0,42 & 3,21 & 0,79 & 28,04 \\
\hline 0,48 & 3,47 & 0,74 & 23,77 \\
\hline 0,55 & 4,13 & 0,71 & 21,36 \\
\hline 0,57 & 4,92 & 0,65 & 18,50 \\
\hline 0,59 & 5,55 & 0,62 & 16,40 \\
\hline 0,61 & 6,87 & 0,58 & 15,20 \\
\hline 0,65 & 7,83 & 0,56 & 13,84 \\
\hline 0,66 & 8,95 & 0,54 & 12,85 \\
\hline 0,80 & 22,36 & 0,52 & 11,49 \\
\hline 0,84 & 29,12 & 0,45 & 10,07 \\
\hline 0,93 & 58,51 & 0,42 & 7,94 \\
\hline 0,94 & 80,90 & 0,39 & 6,09 \\
\hline & & 0,31 & 4,29 \\
\hline
\end{tabular}

*Médias de duas determinações (erros inferiores a 10\%); b.u. = base úmida.

De acordo com os dados de adsorção, o produto só terá sua estabilidade microbiológica assegurada $\left(\mathrm{a}_{\mathrm{w}}<0,6\right)$ quando apresentar umidades inferiores a $7,0 \mathrm{~g} \mathrm{H}_{2} \mathrm{O} / 100 \mathrm{~g}$ b.s. $\mathrm{O}$ menor nível de umidade obtido para o produto foi $9,6 \mathrm{~g} / 100 \mathrm{~g}$ b.s., quando a secagem foi realizada a $90^{\circ} \mathrm{C}$. Para o produto seco a $70^{\circ} \mathrm{C}$, o qual apresentou as melhores características sensoriais, o nível de umidade residual foi de 12,3 g/100 g b.s.; 75\% superior ao valor limitante.

Figura 5 - Isoterma de adsorção para a farinha da fibra residual do maracujá amarelo a $25^{\circ} \mathrm{C}$.

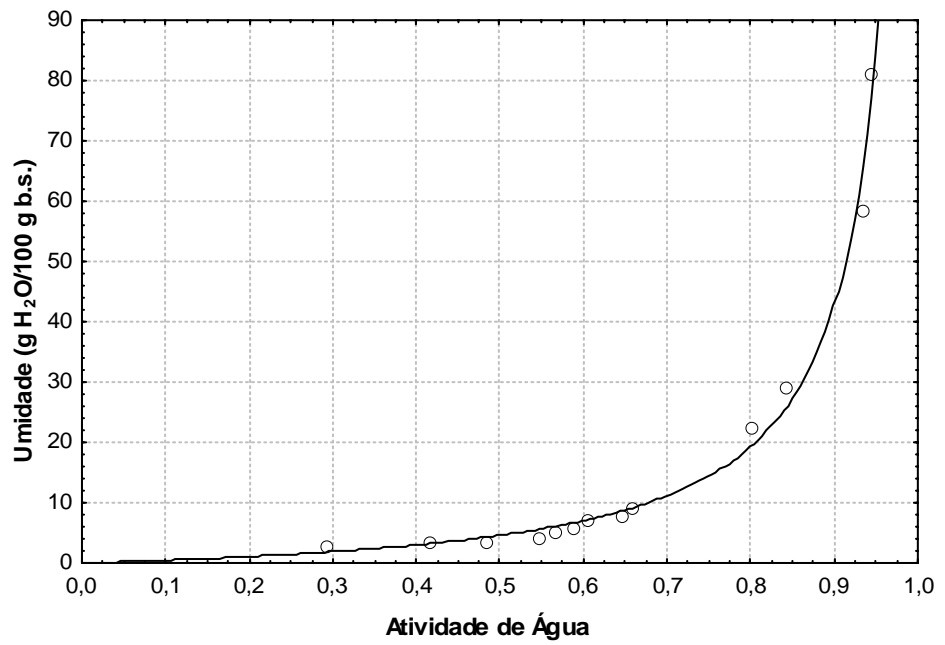


Figura 6 - Isoterma de dessorção para a farinha da fibra residual do maracujá amarelo a $25^{\circ} \mathrm{C}$.

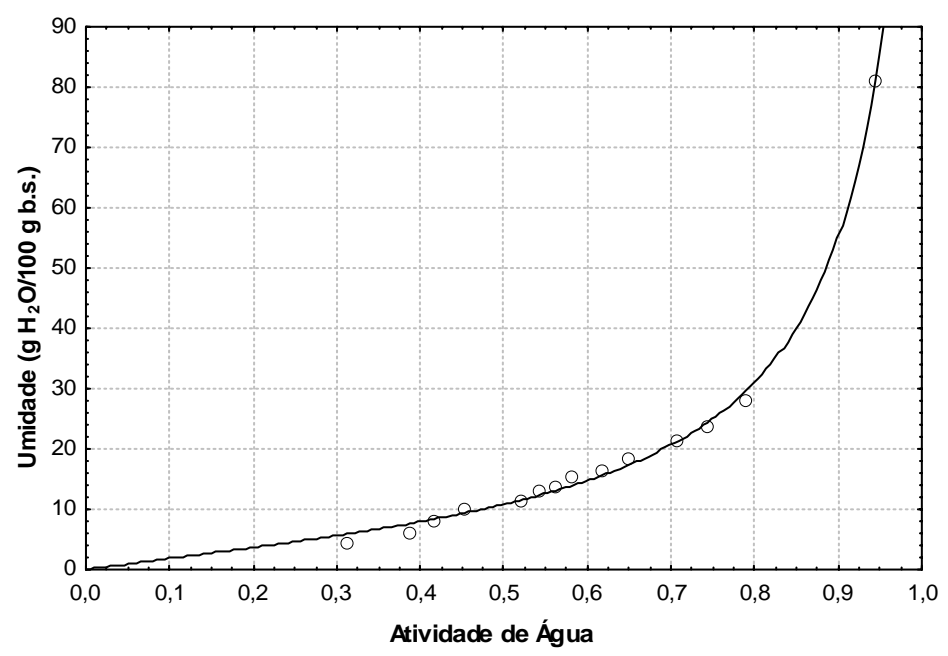

Com base nas umidades residuais e em função do resíduo ser rico em açúcares, que são substratos de interesse de muitos microrganismos, recomenda-se a secagem do mesmo a $70^{\circ} \mathrm{C}$, seguida de secagem complementar a $90^{\circ} \mathrm{C}$. Após a primeira secagem o produto já apresentará umidade bastante reduzida e $a_{w}$ inferior a 0,72 , o que dificultará a ocorrência das reações de escurecimento. Desta forma o produto apresentará uma umidade residual próximo do limite, que lhe assegure estabilidade microbiológica e características sensoriais aceitáveis; demandando para isso um tempo de secagem adicional, $20 \%$ superior ao tempo de secagem a $70^{\circ} \mathrm{C}$.

Na Figura 7 é evidenciado o efeito de histerese para o produto, o qual se apresenta mais pronunciado na região de condensação capilar; sendo característico para produtos que apresentam composição similar ao da farinha obtida.

Os parâmetros dos ajustes do modelo GAB aos dados de adsorção e dessorção de umidade são apresentados na Tabela 5. O coeficiente de determinação $\left(\mathrm{r}^{2}\right)$ comprova os bons ajustes e evidenciam que o modelo pode ser utilizado na predição das isotermas de adsorção e dessorção de umidade do produto estudado. WAUGHON e PENA (2007) obtiveram excelentes ajustes do modelo GAB aos dados de adsorção e dessorção de umidade das fibras residuais do abacaxi, após secagem. 
Figura 7 - Isotermas de sorção para a farinha da fibra residual do maracujá amarelo a $25^{\circ} \mathrm{C}$

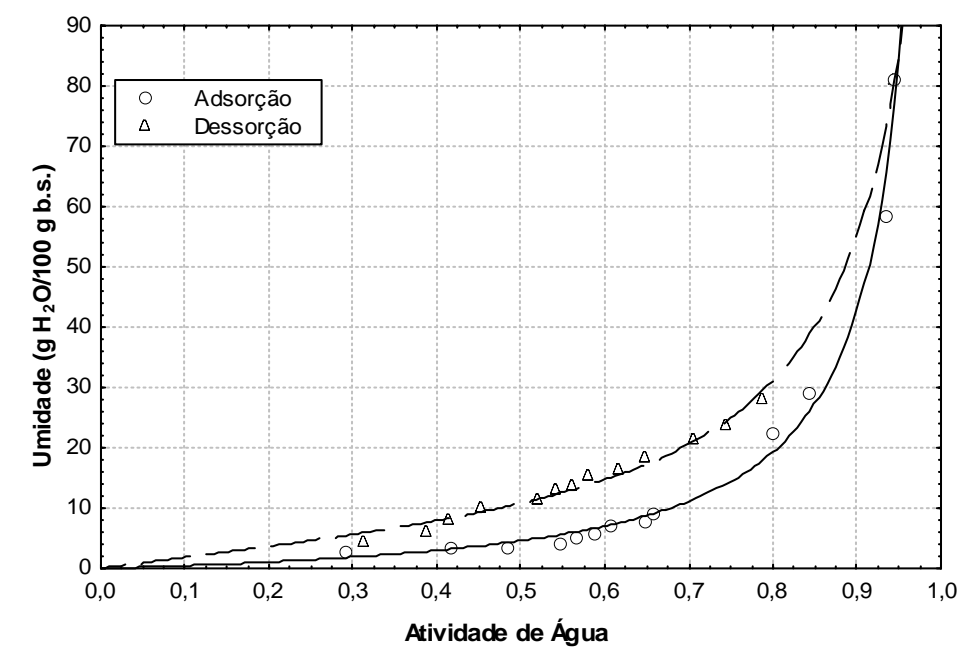

Tabela 5 - Parâmetros para o ajuste do modelo GAB.

\begin{tabular}{ccccc}
\hline \multirow{2}{*}{ Isotermas } & \multicolumn{5}{c}{ Parâmetros } \\
\cline { 2 - 5 } & $\mathbf{m}_{\mathbf{o}}$ & $\mathbf{c}$ & $\mathbf{k}$ & $\mathbf{r}^{\mathbf{2}}$ \\
\hline Adsorção & 5,34 & 0,78 & 0,99 & 0,9880 \\
Dessorção & 8,31 & 2,36 & 0,95 & 0,9972 \\
\hline
\end{tabular}

O valor de umidade na monocamada, para o processo de dessorção (8,31 g/100 g b.s.), comprova por que não se conseguiu secar o resíduo a umidades inferiores a 9,5 g/100 g b.s. Na região da monocamada a água se apresenta fortemente ligada aos solutos (açúcares), necessitando de grande quantidade de energia para ser removida. A tentativa de secar o produto à umidade inferior $\mathrm{a}_{\mathrm{o}}$ pode inviabilizar economicamente o processo.

\section{Conclusões}

Os estudos evidenciaram a possibilidade de aproveitamento do segundo resíduo da industrialização do suco do maracujá amarelo (fibra residual), após secagem a $70^{\circ} \mathrm{C}$, seguida de secagem complementar a $90^{\circ} \mathrm{C}$, em estufa com circulação de ar.

O produto obtido, classificado como farinha das fibras residuais do maracujá amarelo, mostrou-se rico em fibras alimentares, sendo uma alternativa para utilização em dietas que necessitem de tais constituintes.

As isotermas de adsorção e dessorção de umidade da fibra residual do maracujá amarelo, após secagem, apresentaram um comportamento típico de isotermas do tipo III. 
O valor da monocamada para o processo de dessorção validou as condições de secagem utilizadas, porém houve escurecimento do produto, com o aumento da temperatura de secagem.

O modelo de GAB pode ser utilizado, com muito boa precisão, na predição das isotermas de adsorção e dessorção de umidade da fibra residual do maracujá amarelo.

\begin{abstract}
The second residue of the industrialization of the passion fruit juice produced by a paraense industry was studied, through of the drying process. It was submitted to the physical-chemistry characterization, obtaining as composition: $83 \%$ moisture content; $1,8 \%$ protein, $0,2 \%$ fat, $0,6 \%$ ash, $7,1 \%$ total dietary fiber and 7,3\% soluble solids. The kinetics of drying of the residue was studied, in the convective oven at 70,80 and $90^{\circ} \mathrm{C}$. The microbiological quality of the products was verified. The hygroscopic behavior of the product was studied, through of the adsorption and desorption moisture isotherms built at $25^{\circ} \mathrm{C}$. The product presents type III isotherms and monolayer moisture content of $8.3 \mathrm{~g} \mathrm{H}_{2} \mathrm{O} / 100 \mathrm{~g}$ dry solids. The application of the $\mathrm{GAB}$ model in the prediction of adsorption and desorption moisture isotherms of the product was verified. In agreement with drying, hygroscopic and sensorial parameters, the product should be drying at $70^{\circ} \mathrm{C}$, followed by supplementary drying at $90^{\circ} \mathrm{C}$.
\end{abstract}

Keywords: residue; passion fruit; drying; isotherm.

\title{
5. Referências
}

AOAC (Association of Official Analytical Chemists). Official methods of analysis. 16.ed, 3rd rev, 1997.

BRASIL. Agência Nacional de Vigilância Sanitária. Resolução RDC n 263, de 22 de setembro de 2005. Regulamento técnico para produtos de cereais, amidos, farinhas e farelos. Diário Oficial [da República Federativa do Brasil], Brasília 23 set. 2005.

BRASIL. Agência Nacional de Vigilância Sanitária. Resolução RDC no 12, de 02 de janeiro de 2001. Regulamento Técnico sobre padrões microbiológicos para alimentos. Diário Oficial [da República Federativa do Brasil], Brasília 10 jan. 2001.

FERREIRA, C.D. Elaboração de geléia de maracujá utilizando a farinha obtida da casca do maracujá como fonte de pectina. 2004. 25f. Monografia (Especialização em Tecnologia de Alimentos) - Universidade Federal do Pará. Belém, 2004a.

FERREIRA, M.F.P. Obtenção de farinha da casca do maracujá através de secagem visando o aproveitamento do resíduo gerado na indústria do suco. 39f. 2004. Monografia (Especialização em Tecnologia de Alimentos) Universidade Federal do Pará. Belém, 2004b.

ITAL - INSTITUTO DE TECNOLOGIA DE ALIMENTOS. Maracujá. São Paulo: ITAL, 1980. 207p. (Série frutas tropicais, 9).

LIMA, A.A.; FILHO, H.P.S; FRANCELLI, M.; SANCHES, N.F.; BORGES, A.L. A cultura do maracujá. Coleção Plantar, v.13, Brasília: EMBRAPA - SPI, 1994.

MAARA - MINISTÉRIO DA AGRICULTURA E REFORMA AGRÁRIA. Maracujá para exportação: Aspectos técnicos da produção. Brasília, 1996.

MAHAN, L.K.; STUMP, S.E. krause: alimentos, nutrição e dietoterapia. 9.ed., São Paulo: Roca, 1998.

MAROULIS, Z.B.; TSAMI, E.; ARINOS-KOURIS, D.; et al. Application of the GAB model to the sorption isotherms for dried fruits. Journal of Food Engeneering, v.7, p.63-78, 1988. 
MENDONÇA, N.B. Caracterização e secagem do segundo resíduo da industrialização do suco de maracujá em secador de leito fixo. 65f. 2005. Trabalho de Conclusão de Curso (Engenharia Química) - Universidade Federal do Pará. Belém, 2005.

PEREIRA, J. Tecnologia e qualidade de cereais (arroz, trigo, milho e aveia). Lavras: UFLA/FAEPE, 2002.

PROSKY, L.; ASP, N.G.; SCHVEIZER, T.F.; DeVRIES, J.W.; FURDA, I. Determination of insoluble, soluble and total dietary fiber in food and food products: interlaboratory study. Journal of the Association of Official Analytical Chemists, v.71, n.5, p.1017-1023, 1988.

SALWIN, H. Defining minimum moisture contents for dehydrated foods. Food Technology, v.13, p.594-585, 1959.

SILVA, H.L.B. Elaboração de bebidas lácteas adicionadas de xarope do resíduo de maracujá (Passiflora edulis) obtido da centrífuga. Belém, 2002. Trabalho de Conclusão de Curso apresentado a UFPA.

SOUZA, A.C.G; SANDI, D. Industrialização. In: Maracujá: tecnologia de produção, pós-colheita, agroindústria, mercado. Porto Alegre: Cinco continentes, p.305-343, 2001.

STATISTICA for Windows 5.5. Computer program manual. Tulsa: StatSoft, Inc., 2000.

VANDERZANT, C.; SPLITTSTOESSER, D.F. Compendium of methods for the microbiological. Examination and Food. American Public Health Association, 1992.

WAUGHON, T.G.; PENA, R.S. Avaliação higroscópica da fibra residual do abacaxi. Revista Brasileira de Tecnologia Agroindustrial, v.1, n.2, p.83-92, 2007.

\section{Agradecimentos}

A Financeira de Estudos e Projetos - FINEP, pelo apoio financeiro.

\section{Dados do segundo autor:}

Rosinelson da Silva Pena

Faculdade de Engenharia de Alimentos/Instituto de Tecnologia/Universidade Federal do Pará Professor

Rua Augusto Corrêa 1 - Guamá - C P 66075-900 - Belém - PA - Brasil

Fone/Fax: (91)3201-7456

rspena@ufpa.br 